\title{
Vitamin D Receptor Gene Polymorphisms and Risk of Atopic Dermatitis in Chinese Han Population
}

\author{
Yunchao Ou \\ Xiaoli Jiang \\ Huiwen Guan \\ Department of Dermatology, The \\ Central Hospital of Wuhan, Tongji \\ Medical College, Huazhong University of \\ Science and Technology, Wuhan, Hubei \\ Province, 430000, People's Republic of \\ China
}

\begin{abstract}
Background: Studies investigated the associations between four Vitamin D receptor (VDR) common variations and interactions of gene-environment factors and atopic dermatitis (AD) in Chinese population are few.

Methods: In this case-control study, 400 AD patients and 400 controls were genotyped for the FokI, TaqI, BsmI and ApalI variations of VDR genes by restriction fragment length polymorphism analysis. The associations between VDR genes and AD were assessed by univariate and multivariate logistic regression. The interactions between VDR genes and some risk factors were also explored using cross-over analysis. The corresponding odds ratio (ORs) and 95\% confidence intervals (CI) were also calculated.

Results: The FoKI rs2228570 polymorphism was significantly associated with an increased risk of atopic dermatitis in the co-dominant model $(\mathrm{OR}=2.93,95 \% \mathrm{CI}: 1.78-4.82 . P=0.000)$, recessive model $(\mathrm{OR}=2.67,95 \% \mathrm{CI}: 1.68-4.26, P=0.000)$ and dominant model $(\mathrm{OR}=1.38$, 95\% CI: $1.04-1.84, P=0.028)$, and allele model. No significant associations were found among TaqI, BsmI and ApalI polymorphism and AD. The C-A-T-C and C-G-T-T haplotypes significantly increased the risk of atopic dermatitis. For rs2228570, the increased effects were more evident in the subgroups of age $\leq 8$-month, cow milk and mixed, and keeping pet. Interactions between rs2228570 gene polymorphism and family history, age $>8$, and keeping pet increased the AD risk. The rs $2228570 \mathrm{C}$ allele decreased the relative mRNA expression. Conclusion: The FokI rs2228570 C allele of VDR gene could be a risk candidate gene for AD. Interactions between FokI polymorphism and family history and some behaviors may increase the risk of AD.
\end{abstract}

Keywords: vitamin D receptor gene, atopic dermatitis, case-control, interaction

\section{Introduction}

Atopic dermatitis is a chronic, relapsing, inflammatory disease, characterized by the presence of eczematous lesions and pruritus. AD affects nearly $15-30 \%$ of children and $2-10 \%$ of the adult population worldwide. ${ }^{1,2}$ Innate and adaptive immunity have definitive roles in the development, maintenance and flare-up of AD. ${ }^{3,4}$ Skin barrier dysfunctions of AD make the entry of antigens and pathogens into the skin possible. Once they come into skin, they would interact with dendritic cells, and then create a milieu that shapes the immune response to allergy reaction. ${ }^{5}$ Glucocorticoid and antihistamine drugs are used to alleviate clinical symptoms of atopic dermatitis; ${ }^{6}$ However, the long-term use of these drugs has side effects on patients, especially for children. ${ }^{7}$ Therefore, it is of great importance to explore the potential risk factors.

Vitamin D was discovered and named in 1992. Its main source is intestinal absorption and skin synthesis. ${ }^{8}$ Serum 25-hydroxy vitamin D has a long half-life 
and is relatively stable in the blood circulation. Its concentration is considered to be the most reliable indicator to determine the overall vitamin $\mathrm{D}$ status. So, it can be used to determine whether there is vitamin $\mathrm{D}$ deficiency in patients. ${ }^{9}$ The role of vitamin $\mathrm{D}$ is mediated by vitamin $\mathrm{D}$ receptor (VDR) gene is a ligand activated transcription factor that controls gene expression or gene function. ${ }^{10} \mathrm{VDR}$ gene is located on human chromosome 12q12-q14, with 14 exons. Mutations in this gene are associated with type II vitamin D-resistant rickets. A single nucleotide polymorphism in the initiation codon results in an alternate translation start site three codons downstream. Alternatively spliced transcript variants encoding different isoforms have been described for this gene. ${ }^{11}$ It is reported that there are about 470 polymorphism sites in VDR gene, most of which are FokI, TaqI, BsmI and ApalI. ${ }^{12,13}$ A series of gene research results have confirmed that the relationship VDR gene variation and some diseases including allergic diseases. ${ }^{14}$ Previous study found that $\mathrm{AD}$ can benefit from intake of vitamin $\mathrm{D}$, but still remains controversial. ${ }^{15-17}$ This controversial result may be due to difference of exposure to vitamin D. VDR gene variations may affect vitamin D level. Several studies have investigated the associations between VDR polymorphisms and skin diseases (melanoma, vitiligo Behçet disease, psoriasis). ${ }^{18-20}$ Furthermore, two studies from Turkey and German adults found significant associations between VDR gene polymorphisms and AD. ${ }^{21,22}$ Studies among Chinese population are few. Besides, genetic mutation alone may not be enough to induce AD, and the interaction between genes and environmental factors should not be ignored. Study also have confirmed that environmental factors are related to the incidence of $\mathrm{AD}$ in children. ${ }^{23}$ Considering the different genetic background, we investigated the associations between four VDR common variations and AD in Chinese Han's children, and also explored the interactions between VDR gene polymorphism and some factors for the risk of $\mathrm{AD}$.

\section{Methods}

\section{Study Population}

Using a case-control design, we enrolled the patients with atopic dermatitis and healthy controls from the Central Hospital of Wuhan, Tongji Medical College between July 2018 and June 2019. We adopted the Williams criteria recommended by Chinese Society Dermatology for diagnosing atopic dermatitis. ${ }^{24}$ Inclusion criteria for case group: (1) 37 weeks $<$ gestational age $<42$ weeks,
$2.5 \mathrm{~kg}<$ birth weight $<4 \mathrm{~kg}$, normal labor with normal Apgar scale (7-10); (2) patients were confirmed according to the diagnostic standard; (3) age $<12$ months; (4) The infant has no serious diseases affecting growth and development or is accompanied by immune deficiency, congenital diseases, malignant tumors; (5) no other inflammatory skin diseases; (6) The families can cooperate with investigation and data collection. Inclusion criteria for control group: The normal control blood samples were also collected from the physical examination centers and dermatology clinics of the same hospitals, and the "healthy" people were confirmed not to have atopic dermatitis, asthma, allergic rhinitis and other ectopic diseases, and the first-, second-, and third-class relatives had no family history of ectopic diseases. Children with the history of immune or allergy-related diseases were excluded. This study was approved by the ethics committee of the Central Hospital of Wuhan, Tongji Medical College, Huazhong University of Science and Technology. The research was carried out in accordance with the World Medical Association Declaration of Helsinki, and a parent or legal guardian of all subjects provided written informed consent.

\section{Data Collection}

We collected the following data via medical records and questionnaire investigation: age, gender, family history, feeding type (cow milk, breast milk, mixed), parent smoking, keeping pet, history of diseases, growth and development status, history of allergic. The questionnaire was screened according to Williams diagnostic criteria, and the patients with suspected $\mathrm{AD}$ were verified, diagnosed and counted by specialists according to the diagnostic criteria. IgE expression of cord blood was detected using immunofluorescence analysis, and interleukin-4, 5,10 were measured using the double antibody sandwich ELISA technique. The mRNA expression of VDR was detected RT-PCR with Hifair $^{\text {TM }}$ first-strand cDNA synthesis SuperMix and qPCR SYBR Green Master Mix (Yesen, Shanghai, China) using peripheral blood mononuclear cell: a plastic blood bag containing a blood sample into a centrifuge tube adapter, trim after centrifugation, remove the upper plasma layer will be removed in the middle of shallow to shallow layer was removed diluted with normal saline was added; the resulting product into a liquid containing lymphocyte separation centrifuge tube, wherein the product obtained is located in the upper lymphocyte separation medium; centrifugation, draw intermediate 
buffy coat washed, centrifuged supernatant was removed to obtain peripheral blood PBMC.

\section{Genotyping}

We collected peripheral blood $(2 \mathrm{~mL})$ from each patient with case and control in vacutainers containing Ethylene diamine tetraacetic acid (EDTA) anti-coagulant. We used the GoldMag-Mini Whole Blood Genomic DNA Purification Kit (GoldMag. Co. Ltd., Xi'an, China) to extract genomic DNA from the whole blood samples, according to the manufacturer's specifications. The purity and concentration of the extracted DNA were tested by Nanodrop 2000 spectrophotometer (Thermo Fisher Scientific, Waltham, MA, USA). Then, the DNA was stored at $-20^{\circ} \mathrm{C}$ until further experiment use.

Genomic DNA was isolated from whole blood using the QIAamp DNA Blood Mini Kit (Qiagen, Hilden, Germany). The primers designed by the online software Agena Bioscience Assay Design Suite Version 2.0 (https://agenacx. com/online-tools/) were used to amplify the genomic DNA through PCR reaction. Primer sequences for FokI rs2228570 were: 5'-ACCGTGGCCTGCTTGCT-3' (forward) and 5'AGGGTCAGGCAGGGAAGTG-3' (reverse); for TaqI rs731236: Forward primer 5'CAACCAAGACTACAAGTA CCGCGTCAGTGA3', Reverse Primer: 5'CAC TTCGAG CACAAGGGGCGTTAGC3'; for ApaI rs7975232: Forward primer 5'-CAGAGCATGGACAGGGAGCAAG-3', Reverse primer 5'-GCAACTCCTCAT GGCTGAGGTCTCA-3'; for BsmIrs1544410: Forward primer 5'AGTGTGCAGGCG ATTCGTAG3 'Reverse primer: 5'ATAGGCAGAACCATCT CTCAG3. PCR conditions were as the following: initial denaturation at $96^{\circ} \mathrm{C}$ for $5 \mathrm{~min}, 30$ cycles of denaturation at $96^{\circ} \mathrm{C}$ for $45 \mathrm{~s}$, annealing at $55^{\circ} \mathrm{C}$ ( or $62^{\circ} \mathrm{C}$ ) for $40 \mathrm{~s}$, extension at $72^{\circ} \mathrm{C}$ for $60 \mathrm{~s}$. PCR products were sent to Sangon biotech (Shanghai) co., LTD and sequenced by Sanger sequencing method.

\section{Statistical Analysis}

The continuous variables with normal distribution were expressed as mean \pm standard deviation, and were compared between case group and control group using independent $t$ test. The categorical variables were expressed as counts and percents, and Chi-square test was used for comparisons between two groups. The genotype frequencies of four SNPs (TaqI rs731236, ApaI rs7975232, BsmI rs1544410, and FokI rs2228570) among controls were evaluated for Hardy-Weinberg Equilibrium using Chisquare test. The associations between SNPs polymorphism and risk of atopic dermatitis were evaluated using logistic regression, and the odds ratio (OR) with 95\% confidence interval (CIs) was also calculated. Multiple comparisons were evaluated via calculating the false-positive report probability (FPRP) with a prior probability of $0.2 .^{25}$ The linkage disequilibrium haplotype block and haplotypes analysis were performed using the SHEsis online version (http://analysis.bio-x.cn/). ${ }^{26}$ The multivariate logistic regression was performed adjusting for age, gender, parents smoking, feeding type, family history, and keeping pet. Stratified analyses were also performed in the subgroups of gender (boys and girls), age (group by mean), parent smoking (Yes and No), feeding type (breast milk, cow milk, mixed), and family history (Yes and No), keeping pet (Yes and No). Associations between significant SNP and clinical parameters were also evaluated. The cross-over analysis was used for exploring the interactions between significant genetic models and general characteristics for the risk of atopic dermatitis. $P<0.05$ with two sides was considered as significant levels. All statistical analyses were performed using SPSS 23.0.

\section{Results}

\section{Comparisons of General Characteristics Between Case Group and Control Group}

The present study included 400 patients with atopic dermatitis and 400 healthy controls. Table 1 presents the comparisons of general characteristics between case group and control group. The mean age of control group was $10.5 \pm 2.0$ months, and mean age of case group was 5.6 \pm 2.6 months. Significant difference was observed in age between two groups $(P<0.001)$. The ratio of boys was higher in the control than that in the case group $(61.3 \%$ vs $50.7 \%, P=0.003)$. There was no significant difference in parent smoking $(32.8 \%$ vs $39.0 \%, P=0.077)$. We also compared the feeding type of two groups, and no significant difference was observed $(P=0.300)$. Furthermore, the family history ratio was significantly higher in the case group than in the control group $(44.0 \%$ vs $26.2 \%$, $P<0.001)$. The ratio of keeping pet was $29.2 \%$ in the control group that was significantly lower than in the case group $(38.2 \%, P=0.009)$. Several inflammation parameters were also detected. Compared with control group, the case group had higher $\operatorname{IgE}(135.4 \pm 19.5$ vs $31.9 \pm 11.1$, $P<0.001)$, IL6 (141.5 \pm 22.5 vs $118.5 \pm 18.9, P<0.001)$, IL8 $(153.2 \pm 27.6$ vs $104.9 \pm 21.5, P<0.001)$, and IL10 (18.5 \pm 4.1 vs $9.2 \pm 3.1, P<0.001)$ expression level. 
Table I Comparisons of General Characteristics Between Case Group and Control Group

\begin{tabular}{|c|c|c|c|c|}
\hline Factors & Level & Control (n, \%) & Case (n, \%) & $\boldsymbol{P}$ \\
\hline \multirow[t]{2}{*}{$\operatorname{Sex}(n, \%)$} & Girls & 155 (38.8\%) & 197 (49.2\%) & \multirow[t]{2}{*}{0.003} \\
\hline & Boys & 245 (61.3\%) & 203 (50.7\%) & \\
\hline Age (mean (SD)), month & & $10.5 \pm 2.0$ & $5.6 \pm 2.6$ & $<0.001$ \\
\hline \multirow[t]{2}{*}{ Parents Smoking (n, \%) } & No & 269 (67.2\%) & $244(61.0 \%)$ & \multirow[t]{2}{*}{0.077} \\
\hline & Yes & $|3|(32.8 \%)$ & 156 (39.0\%) & \\
\hline \multirow[t]{3}{*}{ Feeding type $(\mathrm{n}, \%)$} & Breast milk & $10 \mid(25.2 \%)$ & 117 (29.2\%) & \multirow[t]{3}{*}{0.300} \\
\hline & Cow milk & 157 (39.2\%) & $159(39.8 \%)$ & \\
\hline & Mixed & 142 (35.5\%) & $124(31.0 \%)$ & \\
\hline \multirow[t]{2}{*}{ Family history (n, \%) } & No & 295 (73.8\%) & $224(56.0 \%)$ & \multirow[t]{2}{*}{$<0.001$} \\
\hline & Yes & $105(26.2 \%)$ & $176(44.0 \%)$ & \\
\hline \multirow[t]{2}{*}{ Keeping pet (n, \%) } & No & $283(70.8 \%)$ & 247 (61.8\%) & \multirow[t]{2}{*}{0.009} \\
\hline & Yes & 117 (29.2\%) & 153 (38.2\%) & \\
\hline IgE (mean (SD)), IU/mL & - & $31.9 \pm 11.1$ & $135.4 \pm 19.5$ & $<0.001$ \\
\hline IL4 (mean (SD)), ng/L & - & $118.5 \pm 18.9$ & $|4| .5 \pm 22.5$ & $<0.001$ \\
\hline IL5 (mean (SD)), ng/L & - & $104.9 \pm 21.5$ & $153.2 \pm 27.6$ & $<0.001$ \\
\hline ILIO (mean (SD)), ng/L & - & $9.2 \pm 3.1$ & $18.5 \pm 4.1$ & $<0.001$ \\
\hline
\end{tabular}

\section{Association Between VDR Gene}

\section{Polymorphism and Atopic Dermatitis}

The Hardy-Weinberg test indicated no significant level for all four SNPs of controls $(P>0.05)$. The genotype and allele frequency distributions of four SNPs (TaqI rs731236, ApaI rs7975232, BsmI rs1544410, and FokI rs2228570) are shown in Table 2. The HWE test indicated that there were no significant deviations for four SNPs $(P>0.05)$. The FoKI rs2228570 was significantly associated with an increased risk of atopic dermatitis in the co-dominant model, recessive model and dominant model, and allele model. Specifically, the CC genotype versus TT genotypes of rs2228570 polymorphism shown a 2.93-fold increased risk of atopic dermatitis (CC vs TT: $\mathrm{OR}=2.93,95 \% \mathrm{CI}: 1.78-4.82$. $P=0.000$ ). Furthermore, the $\mathrm{TC}+\mathrm{CC}$ genotype also significantly increased the risk of atopic dermatitis $(\mathrm{TC}+\mathrm{CC}$ vs TT: $\mathrm{OR}=1.38,95 \% \mathrm{CI}: 1.04-1.84, P=0.028)$. Similar results were also observed in the recessive model (CC vs TT+TC: $\mathrm{OR}=2.67,95 \% \mathrm{CI}: 1.68-4.26, P=0.000)$ and allele model $(\mathrm{C}$ vs T: $\mathrm{OR}=1.45,95 \% \mathrm{CI}: 10.18-1.77, P=0.000)$. The falsepositive report probability (PRPP) was lower than the cut-off value (0.2) that means the associations between rs 2228570 polymorphisms and atopic dermatitis were significant.

After adjusting potential confounding factors, we still found significant association between rs2228570 polymorphism and risk of atopic dermatitis in the co- dominant model ( $\mathrm{CC}$ vs TT: $\mathrm{OR}=3.09$, 95\% CI: $1.46-$ 6.54, $\mathrm{P}=0.003$ ) and recessive model ( $\mathrm{CC}$ vs TT+TC: $\mathrm{OR}=3.17,95 \% \mathrm{CI}: 1.58-6.37, P=0.001)$. No significant associations with atopic dermatitis risk were found for all models of other three SNPs.

The VDR haplotype analysis was also performed. The pair-wise linkage disequilibrium test showed FokI, Bsml ApaI and TaqI were tightly linked (0.95-0.99; $\max 100=$ linked). The results indicated that $\mathrm{C}-\mathrm{A}-\mathrm{T}-\mathrm{C}(\mathrm{OR}=3.55$, 95\% CI: $1.5-8.10, P=0.001)$ and $\mathrm{C}-\mathrm{G}-\mathrm{T}-\mathrm{T} \quad(\mathrm{OR}=2.21$, 95\% CI: $1.46-3.37, P=0.000)$ haplotype significantly increased the risk of atopic dermatitis. The T-A-T-T $(\mathrm{OR}=0.47,95 \% \mathrm{CI}: 0.31-0.72, P=0.000)$ and T-G-T-C (OR=0.61, 95\% CI: $0.41-0.89, P=0.010)$ haplotypes seemed to be associated with decreased risk of atopic dermatitis. Table 3 presents the haplotype analysis of four SNPs for the risk of atopic dermatitis.

\section{Stratified Analysis}

We performed a stratified analysis by gender, parent smoking, feeding type, family history and keeping pet (Table 4). For rs2228570, the increased effects were more evident in the subgroups of age $\leq 8$-month, cow milk and mixed, and keeping pet. Gender, family history and parent smoking subgroups showed similar increased risk effects. We further investigated the associations between rs2228570 polymorphism and 
Table 2 Logistic Regression Analysis of Associations Between Gene Polymorphism and Atopic Dermatitis

\begin{tabular}{|c|c|c|c|c|c|c|c|c|c|c|c|c|c|}
\hline \multirow{3}{*}{$\begin{array}{l}\text { Genotype } \\
\text { rs2228570 }\end{array}$} & \multirow{2}{*}{$\frac{\text { Case }}{n}$} & \multirow[b]{2}{*}{$\%$} & \multirow{2}{*}{$\frac{\text { Control }}{n}$} & \multirow[b]{2}{*}{$\%$} & \multirow[t]{2}{*}{ OR } & \multicolumn{2}{|c|}{$95 \% \mathrm{Cl}$} & \multirow[t]{2}{*}{$P$} & \multirow[t]{2}{*}{ OR } & \multicolumn{2}{|c|}{$95 \% \mathrm{Cl}^{*}$} & \multirow[t]{2}{*}{$P$} & \multirow[t]{2}{*}{ FPRP } \\
\hline & & & & & & & & & & & & & \\
\hline & & & & & & & & & & & & & \\
\hline $\mathrm{TT}$ & 133 & $33.3 \%$ & 163 & $40.8 \%$ & 1.00 & & & & 1.00 & & & & \\
\hline $\mathrm{TC}$ & 200 & $50.0 \%$ & 209 & $52.3 \%$ & 1.17 & 0.87 & 1.58 & 0.298 & 0.92 & 0.57 & 1.47 & 0.713 & 0.001 \\
\hline $\mathrm{CC}$ & 67 & $16.8 \%$ & 28 & $7.0 \%$ & 2.93 & 1.78 & 4.82 & 0.000 & 3.09 & 1.46 & 6.54 & 0.003 & 0.014 \\
\hline $\mathrm{TC}+\mathrm{CC}$ & 267 & $66.8 \%$ & 237 & $47.0 \%$ & 1.38 & 1.04 & 1.84 & 0.028 & 1.14 & 0.72 & 1.79 & 0.583 & 0.001 \\
\hline $\mathrm{TT}+\mathrm{TC}$ & 333 & $83.3 \%$ & 372 & $93.0 \%$ & 1.00 & & & & 1.00 & & & & \\
\hline $\mathrm{CC}$ & 67 & $16.8 \%$ & 28 & $7.0 \%$ & 2.67 & 1.68 & 4.26 & 0.000 & 3.17 & 1.58 & 6.37 & 0.001 & 0.010 \\
\hline $\mathrm{T}$ & 466 & $58.3 \%$ & 535 & $66.9 \%$ & 1.00 & & & & & & & & \\
\hline C & 334 & $41.8 \%$ & 265 & $33.1 \%$ & 1.45 & 1.18 & 1.77 & 0.000 & - & - & - & - & 0.000 \\
\hline \multicolumn{14}{|l|}{ rs 1544410} \\
\hline GG & 133 & $33.3 \%$ & 145 & $36.3 \%$ & 1.00 & & & & 1.00 & & & & \\
\hline GA & 191 & $47.8 \%$ & 172 & $43.0 \%$ & 1.21 & 0.89 & 1.66 & 0.231 & 1.28 & 0.78 & 2.10 & 0.330 & 0.001 \\
\hline$A A$ & 76 & $19.0 \%$ & 83 & $20.8 \%$ & 1.00 & 0.68 & $\mathrm{I} .47$ & 0.993 & 0.87 & 0.48 & 1.59 & 0.657 & 0.003 \\
\hline $\mathrm{GA}+\mathrm{AA}$ & 267 & $66.8 \%$ & 255 & $48.9 \%$ & 1.14 & 0.85 & 1.53 & 0.373 & 1.13 & 0.71 & 1.780 & 0.610 & 0.001 \\
\hline $\mathrm{GG}+\mathrm{GA}$ & 324 & $81.0 \%$ & 317 & $79.3 \%$ & 1.00 & & & & 1.00 & & & & \\
\hline$A A$ & 76 & $19.0 \%$ & 83 & $20.8 \%$ & 0.90 & 0.63 & 1.27 & 0.535 & 0.76 & 0.45 & 1.29 & 0.306 & 0.002 \\
\hline G & 457 & $57.1 \%$ & 462 & $57.8 \%$ & 1.00 & & & & & & & & \\
\hline A & 343 & $42.9 \%$ & 338 & $42.3 \%$ & 1.03 & 0.84 & 1.25 & 0.800 & - & - & - & - & 0.000 \\
\hline \multicolumn{14}{|l|}{ rs7975232 } \\
\hline GG & 110 & $27.5 \%$ & 107 & $26.8 \%$ & 1.00 & & & & 1.00 & & & & \\
\hline GT & 185 & $46.3 \%$ & 177 & $44.3 \%$ & 1.02 & 0.73 & 1.42 & 0.923 & 0.91 & 0.54 & 1.54 & 0.734 & 0.001 \\
\hline $\mathrm{TT}$ & 105 & $26.3 \%$ & 116 & $29.0 \%$ & 0.88 & 0.61 & 1.28 & 0.506 & 0.83 & 0.46 & 1.48 & 0.523 & 0.003 \\
\hline $\mathrm{GT}+\mathrm{TT}$ & 290 & $72.5 \%$ & 293 & $50.3 \%$ & 0.96 & 0.70 & 1.31 & 0.811 & 0.88 & 0.55 & 1.42 & 0.599 & 0.001 \\
\hline $\mathrm{GG}+\mathrm{GT}$ & 295 & $73.8 \%$ & 284 & $71.0 \%$ & 1.00 & & & & 1.00 & & & & \\
\hline $\mathrm{TT}$ & 105 & $26.3 \%$ & 116 & $29.0 \%$ & 0.87 & 0.64 & 1.19 & 0.384 & 0.87 & 0.53 & 1.43 & 0.589 & 0.001 \\
\hline G & 405 & $50.6 \%$ & 391 & $48.9 \%$ & 1.00 & & & & & & & & \\
\hline $\mathrm{T}$ & 395 & $49.4 \%$ & 409 & $51.1 \%$ & 0.93 & 0.77 & 1.13 & 0.484 & - & - & - & - & 0.000 \\
\hline \multicolumn{14}{|l|}{ rs73I236 } \\
\hline $\mathrm{TT}$ & 166 & $41.5 \%$ & 173 & $43.3 \%$ & 1.00 & & & & 1.00 & & & & \\
\hline $\mathrm{TC}$ & 162 & $40.5 \%$ & 164 & $41.0 \%$ & 1.03 & 0.76 & 1.40 & 0.852 & 1.01 & 0.63 & 1.62 & 0.975 & 0.001 \\
\hline $\mathrm{CC}$ & 72 & $18.0 \%$ & 63 & $15.8 \%$ & 1.19 & 0.80 & 1.78 & 0.391 & 1.01 & 0.53 & 1.91 & 0.979 & 0.000 \\
\hline $\mathrm{TC}+\mathrm{CC}$ & 234 & $58.5 \%$ & 227 & $49.2 \%$ & 1.07 & 0.81 & 1.42 & 0.616 & 1.01 & 0.65 & 1.57 & 0.973 & 0.001 \\
\hline $\mathrm{TT}+\mathrm{TC}$ & 328 & $82.0 \%$ & 337 & $84.3 \%$ & 1.00 & & & & 1.00 & & & & \\
\hline $\mathrm{CC}$ & 72 & $18.0 \%$ & 63 & $15.8 \%$ & 1.17 & 0.81 & 1.70 & 0.396 & 1.01 & 0.56 & 1.82 & 0.988 & 0.003 \\
\hline $\mathrm{T}$ & 494 & $61.8 \%$ & 510 & $63.8 \%$ & 1.00 & & & & 1.00 & & & & \\
\hline C & 306 & $38.3 \%$ & 290 & $36.3 \%$ & 1.09 & 0.89 & 1.33 & 0.408 & - & - & - & - & 0.000 \\
\hline
\end{tabular}

Note: *Adjust for age, sex, parents smoking, feeding type, family history, keeping pet.

Abbreviation: FPRP, false-positive report rate.

inflammation factors (IgE, IL6, IL8, IL10) of atopic dermatitis (Table 5). The CC genotype has higher $\operatorname{IgE}$ expression compared to AA genotype $(\mathrm{P}=0.006)$, and similar results were found in the allele $(\mathrm{C}$ vs $\mathrm{A}$, $\mathrm{P}=0.005$ ). The AC genotype carrier of rs 2228570 has also higher IL8 expression compared to AA genotype carrier $(P=0.024)$. No significant associations with other inflammatory factors were found $(P>0.05)$.
Interactions Between rs2228570

\section{Polymorphism and General Characteristics} for the Risk of Atopic Dermatitis

We performed the interaction analysis in recessive model and dominant model of rs2228570 using cross-over analysis (Table 6). Significant interactions among two genetic models and family history, age $>8$, and keeping pet. Specifically, the combination of dominant model/recessive 
Table 3 Haplotype Analysis of Four SNPs of VDR Gene for the Risk of Atopic Dermatitis

\begin{tabular}{|c|c|c|c|c|c|}
\hline Haplotype & Case (Frequency) & Control (Frequency) & $\chi^{2}$ & $P$ & OR [95\% Cl] \\
\hline C-A-G-C & $21.29(0.027)$ & $27.48(0.034)$ & 0.809 & 0.369 & $0.77[0.43-1.37]$ \\
\hline C-A-G-T & $52.23(0.065)$ & $39.63(0.050)$ & 1.834 & 0.176 & $1.34[0.88-2.05]$ \\
\hline C-A-T-C & $25.45(0.032)$ & $7.35(0.009)$ & 10.201 & 0.001 & $3.55[1.55-8.10]$ \\
\hline C-A-T-T & $37.82(0.047)$ & $54.90(0.069)$ & 3.341 & 0.068 & 0.67 [0.44-1.03] \\
\hline C-G-G-C & $43.65(0.055)$ & $23.37(0.029)$ & 6.402 & 0.011 & $1.92[1.15-3.20]$ \\
\hline C-G-G-T & $40.21(0.050)$ & $48.42(0.061)$ & 0.807 & 0.369 & $0.82[0.53-1.26]$ \\
\hline C-G-T-C & $41.22(0.052)$ & $29.58(0.037)$ & 2.004 & 0.157 & $1.42[0.87-2.29]$ \\
\hline C-G-T-T & $72.13(0.090)$ & $34.27(0.043)$ & 14.430 & 0.000 & $2.21[1.46-3.37]$ \\
\hline T-A-G-C & $30.75(0.038)$ & $28.05(0.035)$ & 0.128 & 0.721 & $1.10[0.65-1.85]$ \\
\hline T-A-G-T & $84.41(0.106)$ & $66.48(0.083)$ & 2.354 & 0.125 & $1.30[0.93-1.82]$ \\
\hline T-A-T-C & $57.17(0.07 I)$ & $45.21(0.057)$ & 1.493 & 0.222 & $1.29[0.86-1.92]$ \\
\hline T-A-T-T & $33.87(0.042)$ & $68.90(0.086)$ & 12.759 & 0.000 & $0.47[0.3 \mathrm{I}-0.72]$ \\
\hline T-G-G-C & $41.55(0.052)$ & $57.44(0.072)$ & 2.719 & 0.099 & $0.7 \mid[0.47-1.07]$ \\
\hline T-G-G-T & $90.92(0.114)$ & $100.13(0.125)$ & 0.505 & 0.478 & $0.90[0.66-1.21]$ \\
\hline T-G-T-C & $44.92(0.056)$ & 71.53 (0.089) & 6.554 & 0.010 & $0.6 \mathrm{I}[0.4 \mathrm{I}-0.89]$ \\
\hline T-G-T-T & $82.41(0.103)$ & $97.26(0.122)$ & 1.383 & 0.240 & $0.83[0.6 \mathrm{I}-1.13]$ \\
\hline
\end{tabular}

model and family history was associated with the increased risk of atopic dermatitis compared to without two factors (dominant model: $\mathrm{OR}=3.18,95 \% \mathrm{CI}: 2.07-$ 4.89, $P=0.000$; recessive model: $\mathrm{OR}=6.45,95 \% \mathrm{CI}: 2.78-$ 14.96, $P=0.000)$. Similar results were also found for keeping pets. The $\mathrm{TC}+\mathrm{CC}$ carriers and $\mathrm{CC}$ carriers increased the risk of atopic dermatitis more significantly than those without these two genotypes (TC+CC: $\mathrm{OR}=2.02,95 \% \mathrm{CI}$ : 1.34-3.04, $P=0.001 ; \mathrm{CC}: \mathrm{OR}=3.05,95 \% \mathrm{CI}: 1.47-6.32$, $P=0.002)$. On the contrary, the $\mathrm{TC}+\mathrm{CC}$ genotype and $\mathrm{CC}$ genotype show more significantly decreased effects of atopic dermatitis for age $>8$ months $(\mathrm{TC}+\mathrm{CC}$ : $\mathrm{OR}=0.08$, 95\% CI: $0.05-0.13, P=0.000 ; \mathrm{CC}: \mathrm{OR}=0.21,95 \% \mathrm{CI}:$ $0.11-0.41, P=0.000)$.

\section{Expression of VDR and Gene Maturations}

The mRNA expression level was associated with rs2228570 variants (Figure 1). Our results showed that VDR expression was lower in the atopic dermatitis than that in the control group. There were also significant differences in the VDR expression for rs2228570 polymorphism $(P<0.001)$.

\section{Discussion}

In the present study, we assessed associations among four common SNPs of VDR gene and atopic dermatitis. Several notable findings can be achieved: (1) The FokI rs2228570 gene polymorphism was associated with the increased risk of atopic dermatitis, and TaqI rs731236,
ApaI rs7975232, and BsmI rs1544410 may be not related to atopic dermatitis; (2) A pair-wise linkage disequilibrium was found among four SNPs of VDR gene, and C-A-T-C and C-D-T-T was associated with an increased risk of $\mathrm{AD}$, and T-A-T-T and T-G-T-C present a decreased affect for the risk of AD; (3) For rs2228570, the increased effects were more evident in the subgroups of age $\leq 8$ month, cow milk and mixed, and keeping pet; (4) Interactions between rs2228570 gene polymorphism and family history, age $>8$, and keeping pet increased the AD risk; (5) The increased AD risk associated with the FokI rs2228570 polymorphism could be that VDR expression decreases due to gene variation.

As far as we know, this is the first study about the associations between VDR gene polymorphism and AD in Chinese Han children. Two previous studies from other population setting also reported the effects of VDR gene polymorphisms on AD. Several evident differences should be addressed. Firstly, Heine's study was performed in German adults, and they found the VDR BsmI (rs 1544410) G allele, ApaI (rs7975232) C allele and TaqI (rs731236) T alleles were associated with AD but not FokI (rs2228570). ${ }^{21}$ Kilic et al assessed the association between VDR gene polymorphisms and AD in Turkey adults, and they found the VDR rs1544410 polymorphism was associated with an increased risk of AD. ${ }^{22}$ We found positive association between FokI rs2228570 and AD. Both of two studies and ours have inconsistent results. These results also indicated the VDR gene differently mutates in 


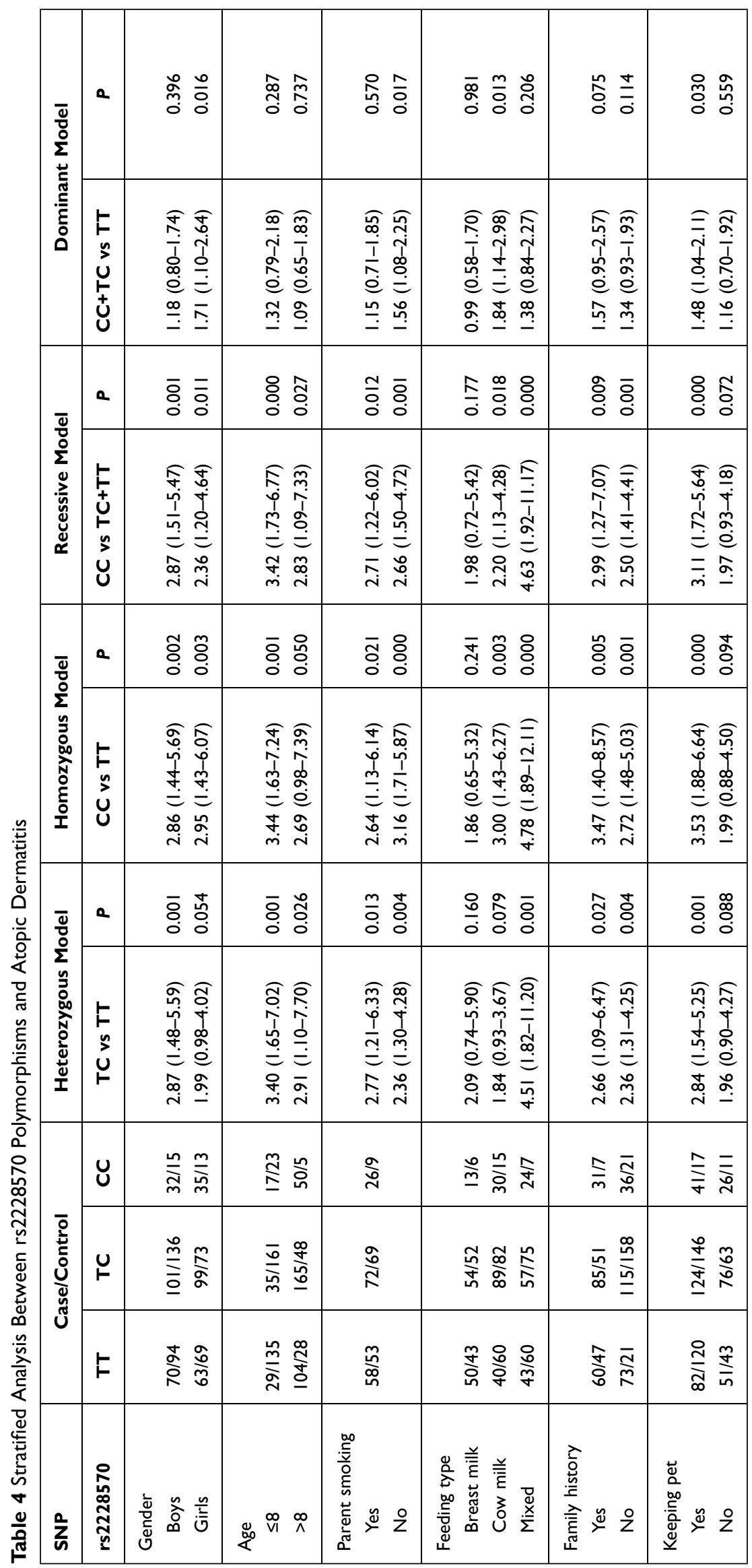


Table 5 Association Between rs2228570 Polymorphisms and Inflammation Factors of Atopic Dermatitis

\begin{tabular}{|c|c|c|c|c|c|c|c|c|c|c|}
\hline \multirow[t]{2}{*}{ Cases } & \multicolumn{2}{|c|}{ AA } & \multicolumn{2}{|c|}{ AC } & \multicolumn{2}{|c|}{ CC } & \multicolumn{2}{|c|}{$\mathbf{A}$} & \multicolumn{2}{|c|}{ C } \\
\hline & $\mathbf{n}$ & $\%$ & $\mathbf{n}$ & $\%$ & $\mathbf{n}$ & $\%$ & $\mathbf{n}$ & $\%$ & $\mathbf{n}$ & $\%$ \\
\hline \multicolumn{11}{|l|}{$\lg E$} \\
\hline High* & 50 & $26.9 \%$ & 97 & $52.2 \%$ & 39 & $21.0 \%$ & 197 & $53.0 \%$ & 175 & $47.0 \%$ \\
\hline Low & 83 & $38.8 \%$ & 103 & $48.1 \%$ & 28 & $13.1 \%$ & 269 & $62.9 \%$ & 159 & $37.1 \%$ \\
\hline$P$ & & & 0.050 & & & 0.006 & & & & 0.005 \\
\hline OR $(95 \% \mathrm{Cl})$ & 1.00 & & \multicolumn{2}{|c|}{$1.56(1.00-2.44)$} & \multicolumn{2}{|c|}{$2.3 I(I .27-4.2 I)$} & & 1.00 & \multicolumn{2}{|c|}{$1.50(1.13-1.99)$} \\
\hline \multicolumn{11}{|l|}{ IL4 } \\
\hline High & 65 & $32.0 \%$ & 106 & $52.2 \%$ & 32 & $15.8 \%$ & 236 & $58.1 \%$ & 170 & $41.9 \%$ \\
\hline Low & 68 & $34.5 \%$ & 94.00 & $47.7 \%$ & 35.00 & $17.8 \%$ & 230.00 & $58.4 \%$ & 164.00 & $41.6 \%$ \\
\hline$P$ & & & 0.460 & & & 0.882 & & & & 0.943 \\
\hline OR $(95 \% \mathrm{Cl})$ & 1.00 & & \multicolumn{2}{|c|}{$1.18(1.18-1.83)$} & \multicolumn{2}{|c|}{$0.96(0.53-1.72)$} & & 1.00 & \multicolumn{2}{|c|}{ I.0I (0.76-I.34) } \\
\hline \multicolumn{11}{|l|}{ IL5 } \\
\hline High & 78 & $38.2 \%$ & 92 & $45.1 \%$ & 34 & $16.7 \%$ & 248 & $60.8 \%$ & 160 & $39.2 \%$ \\
\hline Low & 55 & $28.1 \%$ & 108 & $55.1 \%$ & 33 & $16.8 \%$ & 218 & $55.6 \%$ & 174 & $44.4 \%$ \\
\hline$P$ & & & 0.024 & & & 0.288 & & & & 0.138 \\
\hline OR $(95 \% \mathrm{Cl})$ & 1.00 & & \multicolumn{2}{|c|}{$0.60(0.39-0.94)$} & \multicolumn{2}{|c|}{$0.73(0.40-1.31)$} & & 1.00 & \multicolumn{2}{|c|}{$0.8 \mathrm{I}(0.6 \mathrm{I}-\mathrm{I} .07)$} \\
\hline \multicolumn{11}{|l|}{ ILIO } \\
\hline High & 64 & $33.2 \%$ & 96 & $49.7 \%$ & 33 & $17.1 \%$ & 224 & $58.0 \%$ & 162 & $42.0 \%$ \\
\hline Low & 69 & $33.3 \%$ & 104 & $50.2 \%$ & 34 & $16.4 \%$ & 242 & $58.5 \%$ & 172 & $41.5 \%$ \\
\hline$P$ & & & 0.983 & & & 0.880 & & & & 0.904 \\
\hline OR (95\% Cl) & 1.00 & & \multicolumn{2}{|c|}{$1.00(0.64-1.54)$} & \multicolumn{2}{|c|}{$1.05(0.58-1.88)$} & & 1.00 & \multicolumn{2}{|c|}{$1.02(0.77-1.35)$} \\
\hline
\end{tabular}

Note: *Subjects are grouped by median of IgE, IL4, IL5, ILIO.

different population. Secondly, the present study also performed multivariate regression for adjusting potential confounding factors that increased the results' stability. Previous two studies did not perform such analysis. Thirdly, AD is the combined effect of genes and environmental factors. Therefore, our study also investigated the interactions between identified SNPs and family history and other behaviors. Previous studies did not pay attention to this point. Besides, we also analyzed the association between several inflammation parameters and target SNP polymorphisms. Finally, the present study consisted of relatively large sample size (400 cases and 400 controls), and the sample sizes of previous studies are small (265 cases and controls for one, and 42 cases and 96 controls for the other). The present study provided more information about associations between VDR gene polymorphisms and $\mathrm{AD}$.

The mechanism of $\mathrm{AD}$ still remains unclear. One hypothesis is that, under the interaction of genetic factors including inherent or specific immune response-related gene defects and environmental factors (allergens, scratching, microbial engraftment), the specific cytokine pathways inside the body are activated, which induces systemic allergic inflammation, forms the keratinized cell differentiation defects, eventually leads to the skin barrier function disorder. ${ }^{27}$ As we all know, VDR is mainly mediated by vitamin $\mathrm{D}$ receptor (VDR) gene that is a ligand activated transcription factor that controls gene expression or gene function. Our results also indicated the VDR expression level is lower among population with gene mutations. Vitamin D is involved in immune regulation. Vitamin D can enhance the antimicrobial activity of macrophages and monocytes. The complex of VD, vitamin $\mathrm{D}$ receptor and retinol $\mathrm{X}$ receptor also directly activates the transcription of antimicrobial peptides such as defensin $\beta 2$ and Cathelicin peptides (HCAP18/LL-37), which can enhance the antibacterial ability of the skin.1,25(OH) 2D can directly or indirectly affect the co-stimulatory molecules needed for Langerhans cell activation, such as CD $1 \mathrm{lb}$, inhibit the differentiation and maturation of dendritic 
Table 6 Interaction Between Genetic Models and Factors for the Risk of Atopic Dermatitis

\begin{tabular}{|c|c|c|c|c|c|c|c|c|c|c|}
\hline \multirow[t]{2}{*}{$\mathbf{G}$} & \multirow[t]{2}{*}{ E } & \multicolumn{2}{|c|}{ Cases } & \multicolumn{2}{|c|}{ Controls } & \multirow[t]{2}{*}{ OR } & \multirow{2}{*}{\multicolumn{2}{|c|}{$95 \% \mathrm{Cl}$}} & \multirow[t]{2}{*}{$\chi^{2}$} & \multirow[t]{2}{*}{$P$} \\
\hline & & $\mathbf{n}$ & $\%$ & $\mathbf{n}$ & $\%$ & & & & & \\
\hline $\mathrm{TC}+\mathrm{CC} / \mathrm{TT}$ & Gender & & & & & & & & & \\
\hline- & - & 63 & $47.7 \%$ & 69 & $52.3 \%$ & 1.00 & & & & \\
\hline- & + & 70 & $42.7 \%$ & 94 & $57.3 \%$ & 0.82 & 0.51 & 1.29 & 0.752 & 0.386 \\
\hline+ & - & 134 & $60.9 \%$ & 86 & $39.1 \%$ & 1.71 & 1.13 & 2.57 & 5.817 & 0.016 \\
\hline+ & + & 133 & $46.8 \%$ & 151 & $53.2 \%$ & 0.96 & 0.64 & 1.46 & 0.029 & 0.865 \\
\hline $\mathrm{CC} / \mathrm{TT}+\mathrm{TC}$ & Gender & & & & & & & & & \\
\hline- & - & 162 & $53.3 \%$ & 142 & $46.7 \%$ & 1.00 & & & & \\
\hline- & + & $17 \mid$ & $42.6 \%$ & 230 & $57.4 \%$ & 0.65 & 0.483 & 0.880 & 7.863 & 0.005 \\
\hline+ & - & 35 & $72.9 \%$ & 13 & $27.1 \%$ & 2.36 & 1.212 & 4.596 & 6.480 & 0.011 \\
\hline+ & + & 32 & $68.1 \%$ & 15 & $31.9 \%$ & 1.87 & 0.973 & 3.594 & 3.604 & 0.058 \\
\hline $\mathrm{TC}+\mathrm{CC} / \mathrm{TT}$ & Family history & & & & & & & & & \\
\hline- & - & 73 & $38.6 \%$ & 116 & $61.4 \%$ & 1.00 & & & & \\
\hline- & + & 60 & $56.1 \%$ & 47 & $43.9 \%$ & 2.03 & 1.25 & 3.28 & 8.408 & 0.004 \\
\hline+ & - & $|5|$ & $45.8 \%$ & 179 & $54.2 \%$ & 1.34 & 0.93 & 1.93 & 2.493 & 0.114 \\
\hline+ & + & 116 & $66.7 \%$ & 58 & $33.3 \%$ & 3.18 & 2.07 & 4.89 & 28.545 & 0.000 \\
\hline $\mathrm{CC} / \mathrm{TT}+\mathrm{TC}$ & Family history & & & & & & & & & \\
\hline- & - & 188 & $40.7 \%$ & 274 & $59.3 \%$ & 1.00 & & & & \\
\hline- & + & 145 & $59.7 \%$ & 98 & $40.3 \%$ & 2.16 & 1.57 & 2.96 & 23.012 & 0.000 \\
\hline+ & - & 36 & $63.2 \%$ & 21 & $36.8 \%$ & 2.50 & 1.38 & 4.53 & 10.438 & 0.001 \\
\hline+ & + & 31 & $81.6 \%$ & 7 & $18.4 \%$ & 6.45 & 2.78 & 14.96 & 23.845 & 0.000 \\
\hline $\mathrm{TC}+\mathrm{CC} / \mathrm{TT}$ & Age $>8$ & & & & & & & & & \\
\hline- & - & 104 & $78.8 \%$ & 28 & $21.2 \%$ & 1.00 & & & & \\
\hline- & + & 29 & $17.7 \%$ & 135 & $82.3 \%$ & 0.06 & 0.03 & 0.10 & 110.363 & 0.000 \\
\hline+ & - & 215 & $80.2 \%$ & 53 & $19.8 \%$ & 1.09 & 0.65 & 1.83 & 0.113 & 0.737 \\
\hline+ & + & 52 & $22.0 \%$ & 184 & $78.0 \%$ & 0.08 & 0.05 & 0.13 & 111.652 & 0.000 \\
\hline $\mathrm{CC} / \mathrm{TT}+\mathrm{TC}$ & Age $>8$ & & & & & & & & & \\
\hline- & - & 269 & $78.0 \%$ & 76 & $22.0 \%$ & 1.00 & & & & \\
\hline- & + & 64 & $17.8 \%$ & 296 & $82.2 \%$ & 0.06 & 0.04 & 0.09 & 256.106 & 0.000 \\
\hline+ & - & 50 & $90.9 \%$ & 5 & $9.1 \%$ & 2.83 & 1.09 & 7.33 & 4.917 & 0.027 \\
\hline+ & + & 17 & $42.5 \%$ & 23 & $57.5 \%$ & 0.21 & 0.11 & 0.41 & 23.609 & 0.000 \\
\hline $\mathrm{TC}+\mathrm{CC} / \mathrm{TT}$ & Keeping pet & & & & & & & & & \\
\hline- & - & 82 & $40.6 \%$ & 120 & $59.4 \%$ & 1.00 & & & & \\
\hline- & + & 51 & $54.3 \%$ & 43 & $45.7 \%$ & 1.74 & 1.06 & 2.84 & 4.839 & 0.028 \\
\hline+ & - & 165 & $50.3 \%$ & 163 & $49.7 \%$ & 1.48 & 1.04 & 2.11 & 4.737 & 0.030 \\
\hline+ & + & 102 & $58.0 \%$ & 74 & $42.0 \%$ & 2.02 & 1.34 & 3.04 & 11.346 & 0.001 \\
\hline $\mathrm{CC} / \mathrm{TT}+\mathrm{TC}$ & Keeping pet & & & & & & & & & \\
\hline- & - & 206 & $43.6 \%$ & 266 & $56.4 \%$ & 1.00 & & & & \\
\hline- & + & 127 & $54.5 \%$ & 106 & $45.5 \%$ & 1.55 & 1.13 & 2.12 & 7.385 & 0.007 \\
\hline+ & - & 41 & $70.7 \%$ & 17 & $29.3 \%$ & 3.11 & 1.67 & 5.80 & 15.183 & 0.000 \\
\hline+ & + & 26 & $70.3 \%$ & 11 & $29.7 \%$ & 3.05 & 1.47 & 6.32 & 9.806 & 0.002 \\
\hline
\end{tabular}

cells, affect their functions to induce immune tolerance and inhibit inflammatory response. ${ }^{28-30}$ It has been shown that $1.25(\mathrm{OH}) 2 \mathrm{D}$ regulates skin immune tolerance or immunosuppression by inducing $\mathrm{CD} 4+\mathrm{CD} 25+$
T-regulating (Treg) cells, thereby preventing subsequent antigen-specific $\mathrm{CD} 8+\mathrm{T}$ cell proliferation and IFN- $\gamma$ production. ${ }^{31} \mathrm{VD}$ can not only affect the function of $\mathrm{T}$ lymphocytes, but also affect the function of $\mathrm{B}$ cells. 


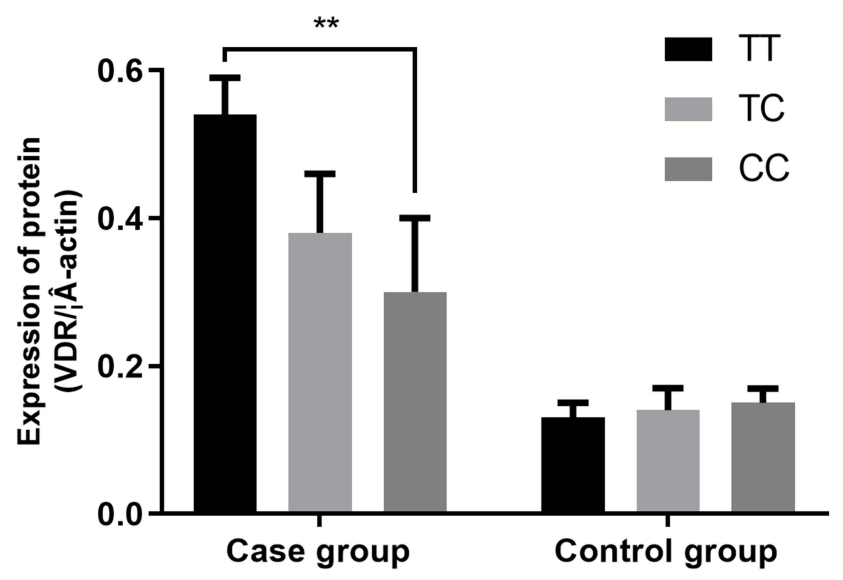

Figure I The mRNA expression level was associated with rs2228570 variants.

Studies have suggested that VD can inhibit the production of antibodies by B lymphocytes. ${ }^{32}$ These results suggest that VD has the ability to regulate both innate and adaptive immunity. Immune dysfunction and impaired skin barrier function are important links in the occurrence and development of atopic dermatitis. VD may play a protective role in AD by regulating the body's innate and adaptive immunity through multiple pathways. Most previous observational studies have shown that VD deficiency is related to the occurrence of $\mathrm{AD}$, and $\mathrm{VD}$ level in $\mathrm{AD}$ patients is significantly decreased and negatively correlated with the severity of the disease in a dose-dependent manner. The veil of the relationship between $\mathrm{VD}$ and $\mathrm{AD}$ was first uncovered by Oren et al. They found that the incidence of $\mathrm{AD}$ was significantly increased in people with VD deficiency. ${ }^{33}$ In 2011, Peroni et al found that 25(OH)D3 levels were significantly reduced in patients with $\mathrm{AD}$ and were inversely associated with disease severity. ${ }^{34}$ Cheng subsequently found in a study of 15,212 Korean adults with $\mathrm{AD}$ that $\mathrm{VD}$ levels were lower in $\mathrm{AD}$ patients than in healthy controls, but not in asthma or allergic rhinitis. ${ }^{35}$ Wang et al demonstrated in a clinical study involving 826 children that not only was VD and AD correlated, but VD levels were negatively correlated with both short-term and long-term disease severity scores. ${ }^{36}$ On the contrary, vitamin D supplementation may help ameliorate the severity of $\mathrm{AD} .^{37}$ These results suggest that VDR gene mutations affect the serum VD level, and further promote AD development via regulating immune response and inflammation.

Several study limitations should be addressed. Firstly, the present study is based on case-control design. The explanations of cause-effect are limited because of the inherent defect of this study design, and some recall bias may exist. Secondly, our study is performed in Chinese Han's children, and the present findings need to be verified in other population setting such as adult.

Thirdly, AD is caused by genes and environmental factors, and other interactions between gene-gene, geneenvironment and $\mathrm{AD}$ should be confirmed in the future study. The common allergic comorbidity is asthma associated with vitamin D gene polymorphisms. Children with asthma have been found to have increased severity of disease with lower concentrations of Vitamin D, which also affect some other diseases such as atopic dermatitis. It is usually uneasy to notice these symptoms for children within one year. Future studies should pay attention to allergic comorbidity. ${ }^{38}$ Finally, although we found VDR gene variations affect the VDR mRNA expression, and the VDR gene polymorphisms may be associated with $A D$ via regulating vitamin $\mathrm{D}$ level. This specific molecular mechanism needs to be further explored. Besides, vitamin $\mathrm{D}$ is a common supplement in newborns, and serum vitamin D level is connected to AD severity and IgE level. The data of subjects are unavailable. The future should pay attention on this.

\section{Conclusions}

Sum it up, this study indicated that the FokI rs2228570 polymorphism of VDR gene could be associated with the increased risk of $\mathrm{AD}$ in Chinese Han children. There are positive interactions between rs2228570 polymorphism and family history, keeping pets for increased risk of AD. The C-A-T-C and C-D-T-T haplotypes occurs in high frequencies in $\mathrm{AD}$ patients than healthy controls. The increased AD risk associated with the FokI rs2228570 polymorphism could be that VDR expression decreases due to gene variation.

\section{Data Sharing Statement}

Please contact the corresponding author for original data availability.

\section{Ethics Approval and Consent to Participate}

This study was approved by Ethics Committee of Central Hospital of Wuhan, Tongji Medical College, and was consistent with the Declaration of Helsinki. Study subjects provided written informed consent prior to participation. 


\section{Patient Consent for Publication}

Not applicable.

\section{Funding}

There is no funding to report.

\section{Disclosure}

The authors declare no conflicts of interest.

\section{References}

1. Nutten S. Atopic dermatitis: global epidemiology and risk factors. Ann Nutr Metab. 2015;66(Suppl 1):8-16. doi:10.1159/000370220

2. Barbarot S, Auziere S, Gadkari A, et al. Epidemiology of atopic dermatitis in adults: results from an international survey. Allergy. 2018;73(6):1284-1293. doi:10.1111/all.13401

3. Guerrero-Aspizua S, Carretero M, Conti CJ, Del RM. The importance of immunity in the development of reliable animal models for psoriasis and atopic dermatitis. Immunol Cell Biol. 2020;98 (8):626-638. doi:10.1111/imcb.12365

4. Niebuhr M, Werfel T. Innate immunity, allergy and atopic dermatitis. Curr Opin Allergy Clin Immunol. 2010;10(5):463-468. doi:10.1097/ ACI.0b013e32833e3163

5. Honda T, Kabashima K. Reconciling innate and acquired immunity in atopic dermatitis. J Allergy Clin Immunol. 2020;145(4):1136-1137. doi:10.1016/j.jaci.2020.02.008

6. Frazier W, Bhardwaj N. Atopic dermatitis: diagnosis and treatment. Am Fam Physician. 2020;101(10):590-598.

7. Lyons JJ, Milner JD, Stone KD. Atopic dermatitis in children: clinical features, pathophysiology, and treatment. Immunol Allergy Clin North Am. 2015;35(1):161-183. doi:10.1016/j.iac.2014.09.008

8. Matsui MS. Vitamin D Update. Curr Dermatol Rep. 2020;2:1-8.

9. DeLuca HF. Vitamin D: historical overview. Vitam Horm. 2016;100:1-20.

10. Saccone D, Asani F, Bornman L. Regulation of the vitamin D receptor gene by environment, genetics and epigenetics. Gene. 2015;561(2):171-180. doi:10.1016/j.gene.2015.02.024

11. Margolis RN, Christakos S. The nuclear receptor superfamily of steroid hormones and vitamin D gene regulation. An update. Ann $N \quad Y \quad$ Acad Sci. 2010;1192:208-214. doi:10.1111/j.17496632.2009.05227.x

12. Zhang JZ, Wang M, Ding Y, et al. Vitamin D receptor gene polymorphism, serum 25-hydroxyvitamin D levels, and risk of vitiligo: a meta-analysis. Medicine. 2018;97(29):e11506. doi:10.1097/ MD.0000000000011506

13. Pesta M. Vitamin D receptor gene polymorphism. Vnitr Lek. 2012;58 (5):381-385.

14. Zhang W, Xu Y. Association between vitamin D receptor gene polymorphism rs2228570 and allergic rhinitis. Pharmgenomics Pers Med. 2020;13:327-335.

15. Lara-Corrales I, Huang CM, Parkin PC, et al. Vitamin D level and supplementation in pediatric atopic dermatitis: a randomized controlled trial. J Cutan Med Surg. 2019;23(1):44-49. doi:10.1177/ 1203475418805744

16. Kim G, Bae JH. Vitamin D and atopic dermatitis: a systematic review and meta-analysis. Nutrition. 2016;32(9):913-920. doi:10.1016/j. nut.2016.01.023

17. Kim MJ, Kim SN, Lee YW, Choe YB, Ahn KJ. Vitamin D status and efficacy of Vitamin D supplementation in atopic dermatitis: a systematic review and meta-analysis. Nutrients. 2016;8:12. doi:10.3390/nu8120789
18. Richetta AG, Silvestri V, Giancristoforo S, et al. A-1012G promoter polymorphism of vitamin $\mathrm{D}$ receptor gene is associated with psoriasis risk and lower allele-specific expression. DNA Cell Biol. 2014;33 (2):102-109. doi:10.1089/dna.2013.2217

19. Aydingoz IE, Bingul I, Dogru-Abbasoglu S, Vural P, Uysal M. Analysis of vitamin D receptor gene polymorphisms in vitiligo. Dermatology. 2012;224(4):361-368. doi:10.1159/000339340

20. Birke M, Schope J, Wagenpfeil S, Vogt T, Reichrath J. Association of vitamin D receptor gene polymorphisms with melanoma risk: a meta-analysis and systematic review. Anticancer Res. 2020;40 (2):583-595. doi:10.21873/anticanres.13988

21. Heine G, Hoefer N, Franke A, et al. Association of vitamin D receptor gene polymorphisms with severe atopic dermatitis in adults. Br J Dermatol. 2013;168(4):855-858. doi:10.1111/bjd.12077

22. Kilic S, Silan F, Hiz MM, Isik S, Ogretmen Z, Ozdemir O. Vitamin $D$ receptor gene BSMI, FOKI, APAI, and TAQI polymorphisms and the risk of atopic dermatitis. J Investig Allergol Clin Immunol. 2016;26(2):106-110. doi:10.18176/jiaci.0020

23. Chiesa FZ. Atopic dermatitis: disease background and risk factors. Adv Exp Med Biol. 2017;1027:11-19.

24. Brenninkmeijer EE, Schram ME, Leeflang MM, Bos JD, Spuls PI. Diagnostic criteria for atopic dermatitis: a systematic review. $\mathrm{Br}$ $J$ Dermatol. 2008;158(4):754-765. doi:10.1111/j.1365-2133.20 07.08412.x

25. Wacholder S, Chanock S, Garcia-Closas M, El GL, Rothman N. Assessing the probability that a positive report is false: an approach for molecular epidemiology studies. J Natl Cancer Inst. 2004;96 (6):434-442. doi:10.1093/jnci/djh075

26. Shi YY, He L. SHEsis, a powerful software platform for analyses of linkage disequilibrium, haplotype construction, and genetic association at polymorphism loci. Cell Res. 2005;15(2):97-98. doi:10.1038/ sj.cr.7290272

27. Novak N. New insights into the mechanism and management of allergic diseases: atopic dermatitis. Allergy. 2009;64(2):265-275. doi:10.1111/j.1398-9995.2008.01922.x

28. Gombart AF, Borregaard N, Koeffler HP. Human cathelicidin antimicrobial peptide (CAMP) gene is a direct target of the vitamin $\mathrm{D}$ receptor and is strongly up-regulated in myeloid cells by 1,25-dihydroxyvitamin D3. FASEB J. 2005;19(9):1067-1077. doi:10.1096/fj.04-3284com

29. Herrmann N, Numm TJ, Iwamoto K, et al. Vitamin D3-induced promotor dissociation of PU.1 and YY1 results in FcepsilonRI reduction on dendritic cells in atopic dermatitis. J Immunol. 2021;206 (3):531-539. doi:10.4049/jimmunol.2000667

30. Novak N, Valenta R, Bohle B, et al. FcepsilonRI engagement of Langerhans cell-like dendritic cells and inflammatory dendritic epidermal cell-like dendritic cells induces chemotactic signals and different T-cell phenotypes in vitro. J Allergy Clin Immunol. 2004;113 (5):949-957. doi:10.1016/j.jaci.2004.02.005

31. Dam TN, Moller B, Hindkjaer J, Kragballe K. The vitamin D3 analog calcipotriol suppresses the number and antigen-presenting function of Langerhans cells in normal human skin. J Investig Dermatol Symp Proc. 1996;1(1):72-77.

32. Yamanaka K, Dimitroff CJ, Fuhlbrigge RC, et al. Vitamins A and $\mathrm{D}$ are potent inhibitors of cutaneous lymphocyte-associated antigen expression. $\quad J$ Allergy Clin Immunol. 2008;121(1):148-157. doi:10.1016/j.jaci.2007.08.014

33. Oren E, Banerji A, Camargo CJ. Vitamin D and atopic disorders in an obese population screened for vitamin D deficiency. $J$ Allergy Clin Immunol. 2008;121(2):533-534. doi:10.1016/j.jaci.2007.11.005

34. Peroni DG, Piacentini GL, Cametti E, Chinellato I, Boner AL. Correlation between serum 25-hydroxyvitamin D levels and severity of atopic dermatitis in children. $B r \quad J$ Dermatol. 2011;164 (5):1078-1082. doi:10.1111/j.1365-2133.2010.10147.x 
35. Cheng HM, Kim S, Park GH, et al. Low vitamin D levels are associated with atopic dermatitis, but not allergic rhinitis, asthma, or IgE sensitization, in the adult Korean population. J Allergy Clin Immunol. 2014;133(4):1048-1055. doi:10.1016/j.jaci.2013.10.055

36. Wang SS, Hon KL, Kong AP, Pong HN, Wong GW, Leung TF. Vitamin D deficiency is associated with diagnosis and severity of childhood atopic dermatitis. Pediatr Allergy Immunol. 2014;25 (1):30-35. doi:10.1111/pai.12167
37. Kim G, Bae JH. Vitamin D and atopic dermatitis: a systematic review and meta-analysis. Nutrition. 2016;32(9):913-920.

38. Ashok N, Kirubakaran R, Saraswathy R. Association of vitamin D gene polymorphisms in children with asthma - a systematic review. Heliyon. 2020;6(9):e4795. doi:10.1016/j.heliyon.2020. e04795

\section{Publish your work in this journal}

The International Journal of General Medicine is an international, peer-reviewed open-access journal that focuses on general and internal medicine, pathogenesis, epidemiology, diagnosis, monitoring and treatment protocols. The journal is characterized by the rapid reporting of reviews, original research and clinical studies across all disease areas. The manuscript management system is completely online and includes a very quick and fair peer-review system, which is all easy to use. Visit http://www.dovepress.com/ testimonials.php to read real quotes from published authors. 